\title{
Occupational asthma after exposure to azodicarbonamide: report of four cases
}

\author{
J-C NORMAND,' F GRANGE,' C HERNANDEZ,' A GANAY,' P DAVEZIES,' \\ A BERGERET, ${ }^{2}$ G PROST ${ }^{1}$
}

From Service des Maladies Professionnelles et Médecine du Travail, ${ }^{1}$ Centre Hospitalier Lyon-Sud, and Institut Universitaire de Médecine du Travail, ${ }^{2}$ Domaine Rockefeller, 69373 Lyon Cedex 08, France

ABSTRACT Azodicarbonamide (Chemical Abstract Service Registry No 123.77.3) is an organic low molecular weight agent used for blowing and foaming plastics. Finely ground azodicarbonamide ca巴 be a pulmonary and sometimes a cutaneous acute sensitiser. Four cases of work related asthma arE reported.

Azodicarbonamide or 1,1' azobisformamide (chemical formula: $\quad \mathrm{H}_{2} \mathrm{~N}-\mathrm{OC}-\mathrm{N}=\mathrm{N}-\mathrm{CO}-\mathrm{NH}_{2}$ is a low molecular weight amide widely used in industry as an expanding and blowing agent for resins and rubbers 1 ; it releases a large volume of gas when heated. Generally, azodicarbonamide is a fine yellow powder but it may also have an orange crystalline appearance.

Its acute oral or inhalation ${ }^{2}$ toxicity is low in animals and no chronic toxicity has been reported. ${ }^{3}$ It is considered as a non-toxic product for man, ${ }^{46}$ although it has a low potential for causing allergic sensitisation.

It is allowed for use in some European countries and since 1962 in the United States to mature and bleach cereal flours. In France it is only allowed as a component of food packaging material.

We here report four cases of lung disease associated with exposure to azodicarbonamide in the plastic industry.

\section{Case 1}

A 50 year old man, a former smoker and a chronic alcoholic, first experienced breathlessness when at work in 1975 and in 1978 presented with an eczematous dermatitis of the face.

Since the end of 1972 he had worked at a small plastic processing factory and been employed as a pigment grinder since the beginning of 1982 . This job consists of preparing pigments and blowing agents in mixing and grinding machines.

He was seen for the first time at the beginning of 1983, with complaints of acute episodes of shortness of breath for three months. His dyspnoea gradually developed five or six hours after he had started work and often appeared in the middle of the night. The symptoms became worse at the end of the week an 9 disappeared during the holidays. They disappeare ${ }^{\prime}$ completely in July 1983, when he was transferree because of his symptoms to the dispatching store.

As he handled over 30 different products, inhalation tests were performed-several months after he had changed jobs-with the following selected agentso prepolymerised polyurethane resin in April 1984 gnd formaldehyde and melamine formaldehyde resit io May 1984. The test results all proved negative and causative agent of his asthma remained unknown. Fig baseline spirometric values showed a mild obstructive syndrome in April 1984 and were thereafter withio normal limits (table).

After we had seen the second patient, we performed, in June 1984, a provocation test with azodicarbon? amide. No immediate reaction occurred but the patient reported having had an attack of asthma in the middle of the following night (figure). When we saw him in February 1985 he had had no further attacks of asthma.

\section{Case 2}

This healthy non-smoking man aged 45 had worked in Selected pulmonary function data (with \% predicted values parentheses)

\begin{tabular}{|c|c|c|c|c|c|}
\hline \multirow[b]{2}{*}{$\begin{array}{l}\text { Case } 1 \\
\text { April } 84 \\
\text { May } 84 \\
\text { June } 84\end{array}$} & \multirow{2}{*}{$\begin{array}{l}F V C(1) \\
\\
4 \cdot 3 \\
4 \cdot 36 \\
4 \cdot 4\end{array}$} & \multirow{2}{*}{$\begin{array}{l}\text { \% pred } \\
\\
(89 \cdot 8) \\
(91) \\
(91.9)\end{array}$} & \multicolumn{2}{|c|}{$F E V_{1}(1) \%$ pred } & \multirow{2}{*}{$\begin{array}{l}\begin{array}{l}F E V_{1} / F V C \\
(\%)\end{array} \\
59.5 \\
63.8 \\
66.4\end{array}$} \\
\hline & & & $\begin{array}{l}2 \cdot 56 \\
2 \cdot 78 \\
2 \cdot 92\end{array}$ & $\begin{array}{l}(73.6) \\
(79.9) \\
(83.9)\end{array}$ & \\
\hline $\begin{array}{l}\text { Case } 2 \\
\text { February } 84\end{array}$ & 3.6 & (96) & $2 \cdot 52$ & $(91 \cdot 6)$ & 70.0 \\
\hline
\end{tabular}



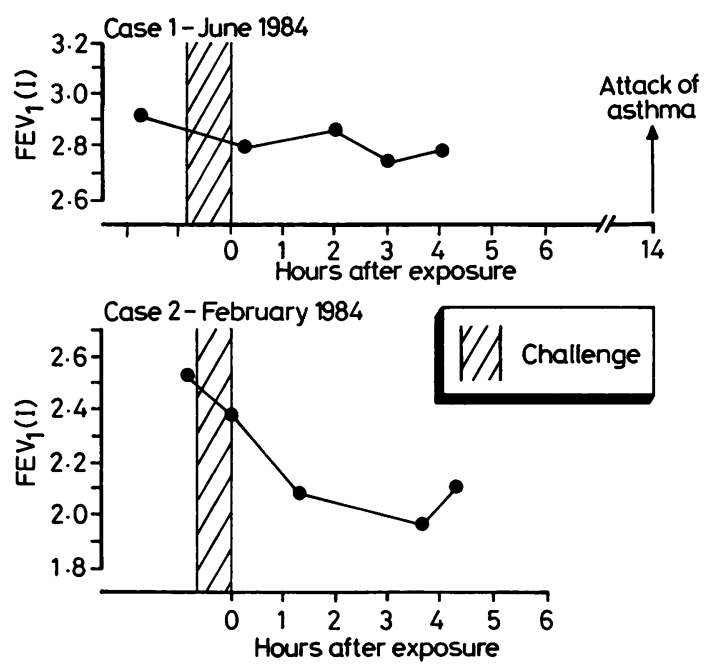

Inhalation challenge to azodicarbonamide in cases 1 and 2.

the same firm as the first patient since 1971. Initially he had been employed at the calender, where in 1973 he developed eczema of the hands and forearms, a condition that he had previously had as a baker in 1959. He later prepared raw material but had to change job because of a recurrence of eczema (1979). In November 1983 he replaced the first patient as a pigment grinder.

We saw him in January 1984 when he complained of shortness of breath at the end of the day's work or a few hours later; the symptoms had started two months before and the patient blamed the blowing agents.

An inhalation test with azodicarbonamide powder was performed in February 1984. All his baseline spirometric values were within normal limits (table). After $\mathbf{4 0}$ minutes exposure, the patient developed an asthmatic reaction ( $22 \%$ fall in $\left.F_{E V}\right)$, reaching a maximum three hours and 40 minutes after the exposure (fig); recovery occurred gradually after five hours.

The patient remained at his job but with improved working conditions. In February 1985 he complained only of vague respiratory symptoms but an accidental re-exposure to azodicarbonamide powder had induced a asthmatic reaction a few months before.

\section{Case 3}

This 50 year old man, an ex-smoker, had worked since 1969 in another small plastic processing factory in which azodicarbonamide was used during one fortnight a year only.
He had reported attacks of asthma or of asthmatic bronchitis requiring the use of antiasthma drugs as soon as he started work during this period every year since 1979. He had no symptoms outside this period.

During the 1974 episode the patient concurrently suffered from eczema of the hands and forearms. This did not appear in the following years as he then wore gloves.

\section{Case 4}

This 54 year old man had worked in the same plastic firm as case 3 since 1977. During an apprenticeship in a bakery he had had chronic eczema and attacks of asthma. As a result he had to change jobs and he had had no further skin or respiratory complaints. Attacks of asthma appeared, however, during the first period of using azodicarbonamide. The symptoms were minimised by preventive medical treatment. The rest of the year he had no asthma and took no treatment.

\section{Discussion}

On the basis of their strong relation to work both with regard to time and location, we are confident that the four cases of asthma described were due to exposures at work. We cannot totally exclude the possibility that substances other than azodicarbonamide were implicated in the cases described; however, the inhalation challenges performed with the azodicarbonamide used by two workers and the clear association with the use of azodicarbonamide in the other two subjects strongly point to this (or possibly a contaminant) as the causative agent.

The causative agent remained unknown until we saw the second patient, who worked on the same job as the first and who associated his complaints with the use of azodicarbonamide. This led us to attempt specific inhalation tests which proved to be positive. In the first case the test, though performed a year after withdrawal of the exposure, was positive, showing a late reaction occurring at home (in France it is current practice not to admit to hospital subjects undergoing inhalation challenge testing). Patients 3 and 4 were not tested because we thought the relation between exposure to azodicarbonamide and asthma was sufficiently established on clinical grounds.

In all cases the attacks of asthma disappeared after exclusion of the agent or changes in working conditions. They have reappeared only after an accidental or controlled medical re-exposure.

Asthma and asthmatic dyspnoea resulting from inhalation of azodicarbonamide powder have been previously described. They were mentioned for the first time in the United States in 1971, after ten cases appeared in a grinding factory ${ }^{7} ; 28$ cases were 
identified in the United Kingdom in 1980 on the basis of a questionnaire study in the plastics industry, ${ }^{8}$ and two cases were described in Canada. ${ }^{9}$ In France azodicarbonamide has been considered as a possible respiratory allergen in the rubber industry. ${ }^{10}$

The characteristics of our four cases of asthma are similar to those described elsewhere. After the first contact and a short period with no signs, the attacks appear suddenly, generally within six months of exposure, ${ }^{79}$ and in $75 \%$ of the cases before the end of the first year. ${ }^{8}$ The attacks happen with delay at the end of the day's work (more than half of them) ) $^{8}$ or late in the night. ${ }^{79}$ The occurrence of symptoms in case 4 on his first industrial exposure to this agent suggests that he had previously been exposed-for instance, as a baker even though the use of azodicarbonamide is not allowed as a food additive in France, or that other substances may cross react with azodicarbonamide.

Our patients have also noticed that their attacks of asthma occur both sooner and last longer as exposure persists for prolonged periods. ${ }^{8}$

We have not been able to assess the prevalence of respiratory complaints in the firms involved, but estimates have varied between $18 \cdot 5 \%$ (151 workers), ${ }^{8}$ $16 \cdot 4-47 \cdot 3 \%$ ( 110 workers), ${ }^{11}$ and $90 \%$ (11 workers) ${ }^{7}$ of those exposed. Not all these subjects, however, had asthma.

Only two patients have had a specific inhalation test with results similar to the second case. ${ }^{9}$

Two of our patients (cases 1 and 4) had had occupational asthma previously, though no increased incidence of azodicarbonamide induced asthma has been reported among atopic people. ${ }^{8}$

Three of our patients (1, 2, and 4) had had eczematous dermatitis, two when working in a bakery. Two cases of allergic contact dermatitis to azodicarbonamide have been reported, one in Italy ${ }^{12}$ (a man working in an industrial bakery had eczema of the face and arms) and the other in the United Kingdom ${ }^{13}$ (a worker in a plastic transforming factory had eczema of the body but not on face or arms). The skin tests have, in both cases, shown a delayed hypersensitivity to azodicarbonamide. The insolubility of azodicarbonamide in the usual solvents, however, renders testing difficult and is thus rarely performed.
The mechanism for the sensitisation, whethe $\overline{\bar{f}}$ immunological or otherwise, has not yet been idenz tified. It may be speculated, however, that as witis other diazo compounds, the high reactivity of the diazo bond of azodicarbonamide may be the basis fo its allergenic potential.

We are very grateful to Dr B Nemery who reviewed the manuscript.

Requests for reprints to: Dr J-C Normand, Service des Maladies Professionnelles et Médecine du Travai $\vec{p}$ Centre Hospitalier Lyon-Sud, 69310 Pierre Bénite France.

\section{References}

1 Institut National de Recherche et Sécurité. Matières plastiques $\overrightarrow{e t}$ adjuvants-hygiène et sécurité. Paris: INRS, 1982:31.

2 Mewhinney JA, Ayres PH, Bechtold WE, et al. The fate of inhaled azodicarbonamide in rats. Fundam Appl Toxicol 1987;8:372-8.

3 Oser BL, Oser M, Morgareidge K, Sternberg SS. Studies of the safety of azodicarbonamide as a flour-maturing agent. Toxic엉 Appl Pharmacol 1965;7:445-72.

4 Merck index. 10th ed. Rahway: Merck \& Co. Inc., 1983:132.

5 National Institute of Occupational Safety and Health. Registry toxic effects of chemical substances. 1981 ed. Vol 2. Cincinnatio US Department of Health and Human Services, 1983:333.

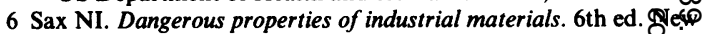
York: Van Nostrand Reinhold Company, 1984:340.

7 Ferris BG, Peters JM, Burgess WA, Cherry RB. Apparent effett of an azodicarbonamide on the lungs. A preliminary reper. Occup Med 1977;19:424-5.

8 Slovak AJM. Occupational asthma caused by a plastics blowing agent, azodicarbonamide. Thorax 1981;36:906-9.

9 Malo JL, Pineau L, Cartier A. Occupational asthma due azobisformamide. Clin Allergy 1985;15:261-4.

10 Danan M, Conso F, Dally S, Diamant-Berger O, Desnoyers Gervais P. Asthmes professionnels dans l'industrie du caout chouc, à propos de 4 observations. Archives des Malad is Professionnelles de Médecine du Travail et de Sécurité Sociale 1984;45:442-3.

11 Whitehead LW, Robins TG, Fine LJ, Hansen DJ. Respirato symptoms associated with the use of azodicarbonamide foaming agent in a plastics injection molding facility. Am J Ind Meg 1987;11:83-92.

12 Nava C, Beretta F, Elena A, Ghizzi A, Pattarin R, Villa L. Be dermatiti allergiche da miglioranti e da altri additivi per farine. Med Lav 1983;74:376-9.

13 Bonsall JL. Allergic contact dermatitis to azodicarbonamide Contact Dermatitis 1984;10:42. 